\title{
Increased tendency to temporary nerve damage with lingual retractor use
}

\begin{abstract}
Pichler JW, Bierne OR. Lingual flap retraction and prevention of lingual nerve damage associated with third molar surgery: a systematic review of the literature. Oral Surg Oral Med Oral Pathol Oral Radiol Endod 2001; 91:395-401
\end{abstract}

Question: Does use of lingual retractor increase risk of nerve damage in third molar retraction?

Objective To review the incidence and recovery of lingual nerve damage after the removal of the third molar by three different techniques.

Data sources Medline, Health Star, Current Contents, Allied and Alternative Medicine, Life Sciences, Web of Science, Nursing Allied Health and the Cochrane library, up to May 1999. The index of the Journal of Oral and Maxillofacial Surgery Clinics of North America 1989-1998 was also searched together with the bibliographies of identified studies.

Study selection Original cases of lingual nerve damage due to third molar removal with $>6$ months follow-up and clinically objective sensory testing. Three different surgical methods were evaluated: buccal approach with lingual retraction $(\mathrm{BA}+)$, buccal approach without lingual retraction $(\mathrm{BA}-)$ and lingual split technique (LS).

Results Although 51 studies addressed the issue of lingual nerve damage only eight met the inclusion criteria. All comparisons of temporary nerve injury rates between the three surgical groups were significant $(\mathrm{P}<0.001)$. A summary of the results is presented below (Table 1).

Conclusion The current literature does not show or support any significant advantage for the use of a lingual flap retractor to protect the lingual nerve during third molar surgery. It does show an increased tendency for temporary injury, however.

Table 1 Nerve injury rates in third molar retraction*

\begin{tabular}{lccccc}
\hline Technique & $\begin{array}{c}\text { Subjects } \\
(\mathrm{n})\end{array}$ & $\begin{array}{c}\text { Temporary } \\
\text { injury } \\
{[\mathrm{n}(\%)]}\end{array}$ & $\begin{array}{c}\text { Permanent } \\
\text { injury } \\
{[\mathrm{n}(\%)]}\end{array}$ & $\begin{array}{c}\text { Risk } \\
\text { ratio } \\
(95 \% \mathrm{Cl})\end{array}$ & $\begin{array}{c}\text { NNT } \\
(95 \% \mathrm{Cl})\end{array}$ \\
\hline $\mathrm{BA}+$ & 3040 & $193(6.3)$ & $19(0.63)$ & & \\
$\mathrm{BA}-$ & 1336 & $8(0.6)$ & $2(0.15)$ & & \\
LS & 2077 & $200(9.6)$ & $3(0.14)$ & & \\
BA vs BA - & & & & $10.6(6.1-18.4)$ & $17(15-21)$ \\
LS vs BA- & & & & $16.1(9.7-26.7)$ & $11(10-13)$ \\
LS vs BA+ & & & & $1.5(1.3-1.8)$ & $30(21-57)$ \\
\hline
\end{tabular}

${ }^{*}$ Results are recalculated from data in the study:

$\mathrm{BA}+$, Buccal approach with retraction; BA-, buccal approach without retraction; LS, lingual split technique; NNT, numbers-needed-to-treat; $\mathrm{Cl}$, confidence interval.

Evidence-Based Dentistry (2002) 3, 107 -108. doi:10.1038/ sj.ebd. 6400145

Address for correspondence: JRW Pichler, c/o Ross Beirne, University of Washington, Department of Oral and Maxillofacial Surgery, Box 357134, Health Sciences Building B-241, Seattle WA 98195, USA.

E-mail: jennibee@u.washington.edu

\section{Commentary}

Third molar surgery is a common procedure carried out by oral and maxillofacial surgeons and surgical dentists and is also undertaken by general dentists. There has been considerable debate in the literature about the rationale for the removal of wisdom teeth and also the resultant morbidity. It is good to see a review addressing morbidity and in particular lingual nerve injury as this can have a more long-term effect than other complications of surgery and therefore be of more significance for the patient.

Jennifer Pilcher and Ross Beirne have carried out a much-needed systematic review of the literature in this area. They evaluate the incidence of lingual nerve damage after third molar surgery and the effect of a lingual nerve retractor on nerve damage, comparing $\mathrm{BA}+, \mathrm{BA}-$ and LS techniques. A comprehensive search strategy for relevant articles yielded 739 of which 51 described lingual nerve injuries. Eight met the inclusion criteria and were included in the review. Seven of these were prospective observational studies and one was a randomised controlled trial (RCT). The proportion of procedures that caused lingual nerve injury was calculated for each study and incidence combined for each surgical technique to present the risk ratios and confidence intervals for each technique.
The authors conclude that the use of a lingual nerve retractor was associated with an increased incidence of temporary nerve damage but was neither protective nor detrimental with respect to the incidence of permanent nerve damage. They found that the studies were difficult to compare, however, because of variance and discrepancies. For example, the assessment of temporary sensory disturbance was made at different timepoints in the studies and the incidence reported may have been exaggerated because of this. There were also differences in study design, study populations, type of anaesthesia, difficulty of surgery, experience of surgeon and type of retractor, which the authors 
recognise would have influenced that results of their review. The only way to account for these variables is to randomly allocate patients to the different surgical techniques.

Although observational studies are useful for investigating incidence, RCT provide more reliable evidence to establish the most preferable surgical technique. Unfortunately there was only one RCT and only a limited quality assessment of it was undertaken. The review may represent the best of the available information available but the results should be interpreted with caution as even these data may not be adequate to provide evidence-based guidance for clinical decision-making.

Paul Coulthard Oral and Maxillofacial Surgery, University Dental Hospital of Manchester, Manchester, UK 